\title{
Too hot to study? Gender and SES differences in the effect of temperature on school performance
}

\author{
Risto Conte Keivabu \\ European University Institute
}

\begin{abstract}
Author: Risto Conte Keivabu, email: risto.conte@eui.eu. Department of Political and Social Science, European University Institute, Badia Fiesolana, Via dei Roccettini 9, 50014, San Domenico di Fiesole (Italy).
\end{abstract}

\begin{abstract}
:
Research highlighted a negative effect of extreme temperature on school performance, especially for ethnic minorities and low status students. This article inquires how SES and gender moderate the effect of temperature on test scores. The focus on gender differences is granted by recent experimental studies that exposed a positive effect of temperature on girl's test scores. In this research, I use the Italian administrative dataset INVALSI combined with measures of temperature on the test day at the provincial level based on the ERA-5 Land database. The results highlight a negative effect of temperatures below $10^{\circ} \mathrm{C}$ and no effect of temperatures above $30^{\circ} \mathrm{C}$ on math test scores, although heterogeneity across gender. Females benefit from higher temperature but males do not. Temperature shocks and school year exposure confirm the pattern. Conversely, no SES differences are observed.
\end{abstract}

\section{Introduction}

The Mediterranean area is highly exposed to the threats of human-induced climate change and global warming (Perkins \& Kirkpatrick, 2020). Temperatures have seen a steady increase with a surge in heatwaves also in early summer when students need to sit essential exams that impact their future educational career. Moreover, the climate shows higher temperature variability with a larger difference between high and low temperatures.

Temperature stress hinders productivity and students' performances in the short and the long run (Goodman et al., 2020; Park, 2018; Dunne et al., 2013; Kjellstrom et al., 2016; Muller et al., 2011). Similarly, there is evidence that sudden changes in temperature are detrimental for human wellbeing (Hovdahl, 2018). However, adaptation and vulnerability to the climate are crucial and social class and gender are critical in this respect. Therefore, sociological contributions are essential to give an understanding of how these phenomena impact vulnerable social groups differently (Klinenberg, Araos, Koslov, 2020; Dietz, Swom, Whitley, 2020).

On the day of the test, low socioeconomic status (SES) students might suffer more from the exposure to uncomfortable temperature due to previous mental and physical conditions. On average, females are more sensitive to extreme temperatures (Schweiker et al. 2018). Moreover, they state to 
prefer warmer environments compared to men and suffer from gender biases in the design of the workplace (Karjalainen, 2011; Chang \& Kajackaite, 2019; Kingma \& Van Marken Lichtenbelt (2015). During the school year, students inhabit different houses and live in separated neighbourhoods being differently affected by the climate. For example, SES is a strong predictor of the ownership of air conditioning or the likelihood of living in fresher areas of a city (Taylor et al. 2018). Therefore, more privileged students might be able to limit exposure to uncomfortable temperatures or compensate for the loss of learning with the help of their parents(Bernardi, 2014; Torche, 2018).

This study contributes to the literature interested in environmental stressors, students achievement and sociodemographic differences in several important ways. First, this is the first study exposing gender differences in the effect of temperature on achievement using observational data that are representative at the national level. Previous studies did not find heterogeneities or adopted experimental designs that, although carrying high internal validity, suffer in terms of representativity at the population level and for other national contexts. Second, I consider temperature shocks as a source of exposure. Temperature shocks permit to understand if sudden changes in temperatures affect performance differently than the exposure to a steady increase of temperature. Thirdly, I explore distributional dynamics and use quintile regression to understand whether heterogeneities are prevalent among bottom or top performers. The analysis hints to possible mechanisms that might explain how temperature affects performance.

I test my hypotheses for the period 2013-2017 in 110 Italian provinces representing the whole national territory. Test scores are from an administrative source and provided by the INVALSI institute for the entire population of 8th graders. Meteorological observations are from ERA-5 and provided at the provincial level. Meteorological data are freely available, have high quality and cover all years and provinces of interest. The results show a negative impact of low temperatures on the test day on math test scores and no effect of hot temperature. However, as in previous experimental studies, such effect is driven by girls doing better in a warmer environments. Conversely, boys perform slightly worse with high temperatures. The findings are confirmed when considering temperature shocks and school-year exposure highlighting the need to construct a school environment that accommodates the preferences of all social groups. In conclusion, the article highlights how sociology can contribute to understand group differences in vulnerability to climate risks. 


\section{Theory}

Extreme temperatures are particularly uncomfortable when concentration is required for a long time and proper insulation or air conditioning is not available. Climate economists and epidemiologist started to study the harmful effects of temperature on human cognitive abilities giving broad attention to heat stress. The focus on heat stress is justified by the concern with global warming and the findings highlighting negative effects of heat on health (Diaz et al., 2018; Barreca et al., 2016), mood (Baylis et al., 2018) and behaviour (Carleton \& Hsiang, 2016). Similarly, studies showed negative effects on human productivity and cognitive abilities (Goodman et al., 2020; Park, 2018; Heal \& Park,2016; Behrer \& Park, 2017; Seppänen et al., 2006). Cold temperature is less researched but also detrimental for cognitive performance (Muller et al., 2011).

Temperatures above $32^{\circ} \mathrm{C}$ or below $10^{\circ} \mathrm{C}$ negatively affect performance, describing an inverted $U$ curve in the relationship between temperature and cognitive abilities (Pilcher, Nadler, Busch, 2002). The mechanisms that explain a decline in performance with high temperatures are a decrease in the blood flow in the brain (Ogoh et al., 2013), fatigue (Nybo et al., 2014) and sleep deprivation (Obradovich et al. 2017; Okamoto-Mizuno \& Mizuno, 2012). Conversely, cold temperature decreases the ability to perform complex tasks and to focus on an activity (Taylor et al., 2015). These conditions emerge outside the bounds of a comfortable temperature. However, the temperature of comfort highly varies, ranging between 15 to $29{ }^{\circ} \mathrm{C}$ depending on the context of analysis and the sociodemographic characteristics of an individual (Schweiker et al., 2018).

Adaptation explains the large variability in the temperature of comfort. Schweiker et al. (2018) explain that the human body adapts fairly quickly to a new climate. Nevertheless, sudden changes to temperature could not be fully compensated by adaptation and negatively affect human wellbeing. For example, Hovdahl (2018) analysed how monthly temperature variation affects mortality in the US. The findings show that temperature shocks are deadlier than exposure to high temperatures. To my knowledge, there are no studies inquiring how temperature variation affects student's school performance. However, shocks are likely to negatively affect educational attainment, whit sudden increseases or decreases in temperature. Students can better adapt to a steady increase or decrease in temperature but could be less able to adapt to sudden changes. For example, exposure to temperature shocks could determine wrong clothing choices or failures in physical adaptation to the new climate.

Exposure can be inquired from two perspectives: short or long term. Short-term exposure is understood as the effect of temperature on the day of the test. Conversely, the long-term view is conceived as the accumulation over time of the negative impact of temperature on learning through repetitive exposure. Next, I explain the two kinds of exposure thoroughly. 


\section{Short and long term exposure to uncomfortable temperature}

Poor environmental conditions on the day of the test could impair concentration and hamper performance. Uncomfortable temperature is one of such conditions. Experimental studies demonstrated a decrease in performance in individuals that executed a task at high or low temperatures (Seppänen et al., 2006; Muller et al., 2011)). Similarly, lower productivity in industrial workers has been observed during hot days (Dunne et al., 2013). Park (2018) inquired students in New York and how their performance varied based on the temperature on the day of the test. The analysis showed a decrease in performance with higher temperatures but only for students in schools without air conditioning.

The performance of a student reflects the skills accumulated throughout the school year in school and at home. For example, the schooling effect implies that exposure to school enhances test performance. However, meteorological factors might hinder the positive effects of schooling or studying at home. Uncomfortable temperature limits the learning capacity of students in the short term with cumulative repercussions on test scores. Goodman et al. (2020) analyzed how exposure to sweltering temperature during the school year affected test performance. A negative effect on the exam scores confirmed that heat impaired learning during the school year but only in schools without air conditioning and especially for blacks and poor pupils. Taking a medium-term perspective, Cho (2017) focused on students in South Korea inquiring the influence of summertime heat on test scores in the fall. The author observed a small decrease in test scores determined by days with temperatures above $34^{\circ} \mathrm{C}$. Overall, the results suggest that heat disrupts learning abilities, although the threshold above which negative effects are observed dependes on the geographical context.

The long-term adverse effects of meteorological factors on student's performance are also explained by the allocation of time. Blaabæk (2020) found that cloudy days increase the time spent reading and performance in the reading test. Similarly, sunny days when coupled with sweltering weather could enhance test scores as students prefer to stay home and read instead of being exposed to extreme temperatures outside. Moreover, during a heatwave, students might take care of their older relatives and reduce their time dedicated to learning (Cho, 2017). However, the effect of weather on time use changes depending on the weekdays. Laidley \& Conley (2018) found sunny days to incentivize outdoor activities with positive effects on cognitive abilities and test scores. Goodman et al. (2020) found no negative impact of temperature on learning when analyzing weekends and festivities, suggesting that heat has only a negative influence when pupils are in school. Therefore, 
differences in the effects of temperature on school outcomes could vary based on weekdays and weekends.

\section{Sociodemographic differences in temperature sensibility and compensatory behaviour}

Extreme temperatures are uncomfortable for the whole population but some students may suffer more than others. Three major factors account for this heterogeneity. First, people vary in their likelihood of being exposed to extreme temperature. Secondly, individuals differ in their perceptions of what constitutes an uncomfortable temperature. Thirdly, students vary in the ability to compensate for the negative effects of an unexpected event on learning. Socioeconomic status and gender play a major role in shaping climatic vulnerabilities.

\section{Socioeconomic status and temperature}

Material resources affect how individuals can cope with extreme temperatures. The most common tools to regulate body temperature are clothing, air conditioning and heating systems. Low SES students are less likely to attend schools with air conditioning, to possess adequate clothing and live in houses equipped with a good heating system (Goodman et al., 2020; Taylor et al., 2018). Therefore, poorer students are more likely to be exposed to an uncomfortable temperature.

The acute stressor represented by heat might be more detrimental for low SES students. Physical conditions related to the body mass index (BMI), the metabolic rate and habituation affect the preferred environmental temperature (Schweiker et al., 2018). Socioeconomic status affects the likelihood of being overweight and the sense of control in life. Both factors explain variation in preferences on temperature and are correlated with SES (Basto-Abreu et al., 2017; Daganzo, Bernardo \& Wakefield, 2018).

The unfortunate exposure to temperature stress might have long-lasting effects on student learning. For example, losing the explanation of a book chapter might affect the ability to learn the following parts of a topic. Therefore, parents play an essential role in compensating for the adverse events that might affect their children learning (Torche, 2018; Bernardi, 2014). The compensatory advantage theory(CAT) is relevant to comprehend how long-term exposure to heat might affect performance in a test at the end of the school year. For instance, high SES students that are unable to concentrate in class during a particularly hot day can catch up the lesson at home with the help of their parents. Conversely, low SES students lack air conditioning and the help of their parents in the home environment falling behind. 
So, low SES students are more likely to be exposed to extreme temperatures, less able to endure uncomfortable weather and their parents cannot compensate for negative effects on learning.

\section{Gender differences in temperature comfort: physiological and sociological explanations}

Men and women differ in their sensibility and preferences on temperature. The temperature of comfort ranges between 15 to $29^{\circ} \mathrm{C}$, and the factors that influence these preferences are psychologically, physiologically and geographically determined (Schweiker et al., 2018). On average, women have a higher temperature of comfort and are more sensitive to extreme temperatures. What seems to best explain gender differences in temperature preferences is the metabolic rate (Karjalainen, 2011; Schweiker et al., 2018). On average, men have a higher metabolic rate that keeps the body at higher temperatures compared to women.

Also, social norms and biases influence gender differences. Clothing plays a vital role in temperature control. As the saying goes: "There is no bad weather, only bad clothing". Proper clothing helps to protect from cold and feel fresher on hot days. However, gendered social norms influence how people dress. For example, males may wear a suit and females skirts in an office setting. Therefore, men prefer lower temperatures than women that could find uncomfortable a cold office. Moreover, Kingma \& Van Marken Lichtenbelt (2015) show that workplaces set the internal temperature based on the thermal comfort of men, decreasing women performance. Similarly, Perez (2019) in her popular book "Invisible Women: exposing data bias in a world designed for men" shows how biases in data collection shape a world fit for men but not for women. For example, the design of the work environment could determine neck and shoulder disorders in women but not in men requiring special attention (Cote, 2011).

However, is the gender difference in thermal comfort large enough to affect cognitive abilities and test performance? In an experimental setting, Chang \& Kajackaite (2019) tested men's and women's performance in cognitive tasks at different temperatures. The results exposed women's higher attainment in a warmer environment. Conversely, men's achievement slightly suffered at high temperatures, particularly in reading. The authors show that effort explains part of the heterogeneity in the results. Respectively, women increase the number of answers given at higher temperatures, and the opposite happens for men. These results have not been replicated with observational data raising questions on the generalizability of the findings.

The compensatory advantage theory has not been yet inquired related to gender in the literature. However, differences in the amount and quality of time parents invest with their sons and 
daughters might suggest the existence of compensatory advantages for one of the sexes (Milligan \& Baker, 2013 ; Dossi et al,. 2019). For example, a preference for boys might lead to a lower investment in girls math competences when they suffer from a negative grading determined by an unpredicted event. Conversely, boys might get support from their parents and catch up in their math abilities. Nonetheless, in this context, the assumptions on the CAT applied on gender are merely speculative and the testing should be tried in another venue.

\section{Italy, climate change and the perils of global warming}

Climate change and global warming affect countries unequally (Bathiany et al., 2018 \& Perkins \& Kirkpatrik, 2020). Some areas of the world are more exposed to the new climate risks. Italy is located in the Mediterranean area that is expected to highly suffer from climatic dangers such as droughts and heatwaves. Here, temperatures have already seen a steady increase with a surge in hot days and sudden changes in climate. Unfortunately, these phenomena are expected to intensify in the future. Students are a vulnerable group that suffer from the exposure to uncomfortable climatic conditions. For example, in early summer, they need to sit essential exams that impact their future educational and work career.

To inquire how short- and long-term exposure to temperature affects students school performance in Italy, I merge data from a national standardized test run by the INVALSI governmental agency with meteorological data from ERA-5.

\section{INVALSI data}

In Italy, students in $8^{\text {th }}$ grade, are required to sit a national test developed by a governmental agency called INVALSI. The test provides a national evaluation of the competencies attained by students in Mathematics and Reading. The test has high stakes for $8^{\text {th }}$ graders affecting their graduation grade from middle school. The grade is critical as it might influence the choice of high school. The test is mostly taking place in the third week of June, starts at 8:30 in the morning and finishes approximately at 12 am (reading test followed by mathematics).

An important feature of this dataset is that it comprehends the whole population of Italian students aged, on average, 14 years old. Secondly, the data provide a neutral assessment of the student's competencies providing an individual score standardized at the national level. Thirdly, the 
timing of the test, in mid-June, permits to capture how unexpected weather on the day of the test and during the school year affects educational achievement.

A drawbak of the INVALSI data is that information on parental background is collected only on a subsample of students, reducing the analytical sample used in the analysis. Moreover, the dataset gives precise geographical information only at the provincial level.

Table 1 reports the date of the examination and sample size before and after listwise deletion by year. The sample used in the analysis comprises students from all 110 Italian provinces and, therefore, representative of the whole country.

[insert Table 1 about here]

Meteorological data: ERA5-Land \& E-OBS

The ERA5- hourly Land dataset provides the most accurate historical meteorological information for the whole Italian territory. The ERA 5 is curated by the European Climate Data Store (CDS) implemented by the European Center for Medium-Range Weather Forecast (ECMWF). The data comprises hourly observations on temperature and other meteorological variables from 1981 to the present day with a high geographical resolution.

I calculated the mean temperature as the mean hourly average temperature measured in the grids that fall within the area of a province on the test day. For the school year temperature, from school start to the day of the test, I used the ERA-5 to capture daily mean temperatures for all provinces.

\section{The temperature on the day of the test and student's performance}

Figure 1 shows how test results negatively correlate with the average temperatures on the day of testing. Math and Reading scores are lower in the provinces where temperatures are higher. The evidence matches previous explorations using PISA or US data (Goodman et al., 2020). However, such correlational evidence may be biased by confounding factors. For example, the Northern regions of Italy are economically more developed and achieve on average higher grades compared to the South that hosts also higher temperatures. 
Therefore, to reduce potential issues of confounding between temperature on the day of the test and student's performance, I use the following econometric model:

$$
Y i p \mathrm{t}=\beta \mathrm{o}+\beta T E M P_{p t}^{j}+\mathrm{Xipt}+\mathrm{as}+\mathrm{cp}+\operatorname{\varepsilon ipt}
$$

Yipt represents the standardised score of a student $i$ in the province $p$ in the year $t$. TEMP represent temperature in the categories: $<10^{\circ} \mathrm{C}, 10-15^{\circ} \mathrm{C}, 15-20^{\circ} \mathrm{C}, 20-25^{\circ} \mathrm{C}, 25-30^{\circ} \mathrm{C}$ and $>30^{\circ} \mathrm{C}$. I choose to use a categorical variable for temperatures as it better captures nonlinearities in the relationship between temperature and test scores. The reference is the temperature of comfort 20$25^{\circ} \mathrm{C}$. Worthnoting is that mean temperatures refer to the specific time of testing. The students sit the Reading test from 8:30 am until around $10 \mathrm{am}$. So, I calculate the mean temperature from 8 am to $10 \mathrm{am}$. Conversely, Mathematics test starts after a short break at $10 \mathrm{am}$ finishing around 11:30 am. Measuring the mean temperature during each test permits to take into consideration temperature fluctuations during the day. In this way, I contribute to the previous literature that relied only on daily mean temperature instead of test time temperature.

In equation (1), I include a vector Xipt that captures control variables for migration status, SES, gender. Migration status divides students in three categories: natives, $1^{\text {st }}$ generation migrants and $2^{\text {nd }}$ generation migrants. Students' SES is captured by their mother's educational level. I classify "Low SES" the students with a mother with middle school education or lower, "Medium SES" if the mother has higher than middle school but lower than university education and "High SES" the students with a mother with a college degree or higher. For gender, I use the dichotomous variable provided by the INVALSI dataset. One of the main main limits of my measure of temperature exposure is the variability in temperature within the province. To control for it, I insert altitude of the school, captured in the equation by as, to account for the change in temperature within provinces determined by schools being located at higher elevations.

In equation (2), I insert the variable $\beta T C H A N G E$ to capture the effect of variation in temperature from the day preceding the test. The variable is constructed calculating the difference between the average temperature on the day of the test and the day preceding the test. The variable is categorical and captures temperature change in five ranges: $<-3^{\circ} \mathrm{C},-3$ to $0^{\circ} \mathrm{C}, 0$ to $3^{\circ} \mathrm{C}, 3$ to $7^{\circ} \mathrm{C},>$ $7^{\circ} \mathrm{C}$. The category 0 to $3^{\circ} \mathrm{C}$ is set at the reference level.

$$
Y i p \mathrm{t}=\beta \mathrm{o}+\beta T C H A N G E_{p t}^{j}+\beta T E M P_{p t}^{j}+\mathrm{Xipt}+a s+\mathrm{cp}+\varepsilon i p t
$$


The main assumption of the approach in equation (1) and (2) is that individuals are comparable throughout time in the same unit of analysis, in this case, the students attending the test in the same province in the different years (Hsiang, 2016; Cho, 2017). Therefore, the model relies on the random variation in temperature in a certain province in the different years in which students attend the test to identify the relationship of temperature with student's test scores.

Therefore, in the equations (1) and (2) I introduce cp to capture province fixes effects. Compared with Cho(2017), I choose not to use year fixed effects as these make the interpretation of the results more complicated and do not help to answer the question at hand (Kropko \& Kubince, 2020). Moreover, running the analysis with year fixed effects does not change the substantive interpretation of the findings (for a comprehensive discussion on the use of fixed effects, I refer to Kropko \& Kubinec, 2020).

[insert Table 2 about here]

Table 2 presents the results for the whole sample. In model 1, the coefficients show low temperatures to decrease test scores in Mathematics by 0.18 standard deviations for temperatures $<10^{\circ} \mathrm{C}$ and by 0.1 standard deviations in the $10-15^{\circ} \mathrm{C}$ range. Conversely, warm temperature in the 25 $30^{\circ} \mathrm{C}$ range increases math scores by 0.005 standard deviations. In the case of reading, the size of the effects is small and not statistically significant with the exception of temperature $>30^{\circ}$ that shows a negative effect of 0.01 standard deviations. In models 3 and 4, I introduce the variable capturing temperature change. Worth noting is that the coefficient of the temperature categories do not subtantively differ introducing this latter variable. Temperature change in the range $>3^{\circ} \mathrm{C}$ negatively affects performance, especially in math, while a larger effect size of 0.016 standard deviations is found for temperature shocks of $>7^{\circ} \mathrm{C}$. Interestingly, a sudden reduction in temperature shows a positive effect of 0.19 standard deviations. However, the results might be determined by the lack of extreme cases, for instance of a reduction in temperature of 7 or more ${ }^{\circ} \mathrm{C}$.

Overall, the results highlight extreme temperatures and sudden changes in temperature to affect students test performance. Nonetheless, large heterogeneities between social groups might be hidden in the population and will be inquired in the following analysis.

\section{Heterogeneity in the sensitivity to extreme temperature and temperature shocks}


Figure 2 shows that SES does not moderate the effect of temperature on math test scores. Conversely, a small negative impact is seen for Low SES student's reading scores when exposed to temperature $>30^{\circ} \mathrm{C}$. Gender identifies the largest heterogeneities, but only in the Math test and at high temperatures. Low temperatures hinder performance for boys and girls. Conversely, with temperatures $>30^{\circ} \mathrm{C}$ girls increase their scores by 0.11 standard deviations in Math and boys show a small decrease. The size of the effect is not large but enough to almost fully eliminate the gender gap in math. Therefore, the gender gap is lower at higher temperatures. Followingly, I will investigate gender differences only, as these are the only ones to show substantive heterogeneities.

Figure 3 displays how temperature change affects test scores by gender. The only substantive results pertain math. A sudden decrease in temperature of more than $3^{\circ} \mathrm{C}$ decreases girls performance but profits boys. An increase in temperature improves girl's performance in math and the oppositve is true for boys. Therefore, results confirm the pattern observerd in figure 2: Boys perform better when it is colder and girls when it is warmer.

\section{[insert Figure 3 about here]}

\section{Long term effect of temperature on performance}

Temperature during the day of the test affects performance. However, cumulative effects during the school year can be reflected in the score on the day of the test. Therefore, I explore the long-term effects of temperature looking separately at in-school and out of school exposure. The empirical strategy is the following:

$$
\text { Yipy }=\beta o+\beta T S C H O O L Y E A R_{p y}+\mathrm{Xipy}+\mathrm{cp}+a s+\varepsilon i p t
$$

The in-school measure of exposure is constructed calculating the mean temperature of each day during a school year excluding weekends and festivities. Similarly, I calculate exposure for out of school days calculating only the mean temperature during weekends and festivities. Therefore, model (3) differs from model (1) only in the variable of exposure that in this case is $\beta T S C H O O L Y E A R_{p y}$ when looking at school days and $\beta$ TOUTSCHOOL $L_{p y}$ for out of school-year days. 
The results show a negative relationship between school-year temperature and test scores in Math (0.013 standard deviations) and Reading (0.006) standard deviations. Results by SES and gender are similar to the ones observed looking at exposure on the day of the test. There are no heteroneneities by SES in the case of math but a positive relationship with reading. Gender differences highlight girls doing better in math during a warmer school year.

\section{Temperature and exposure during festivities}

Table 4 shows how out of school exposure influences test performance. Out of school temperature has a positive effect on math scores of approximately 0.02 of a standard deviation but no substantive effect on reading. The interactions show Medium and High SES students to have higher scores in reading when the temperature is higher compared to Low SES students. The interaction with sex show girls do slighlty better with higher temperatures during festivities.

\section{[insert Table 4 about here]}

\section{Discussion}

Temperature affects cognitive abilities, but individuals expose differences in their vulnerability.

On the day of the test, high temperature has no substantial effect on Italian student's test scores in math but on reading and SES does not play a significant role in stratifying the effects of exposure. Conversely, a sudden increase in temperature, relative to the day preceding the test, determines a negative impact on math and reading scores. Similarly, cold temperatures negatively affect test performance. Results are not contrasting but rather complementary with the previous literature that showed a negative effect of high temperature on school grades (Goodman et al., 2020). Temperatures around $30^{\circ} \mathrm{C}$ might not be considered problematic for Italian students. Similarly, Cho (2017) exposed that only temperatures above $34^{\circ} \mathrm{C}$ are detrimental for students learning in South Korea. Conversely, Park (2018) showed that negative effects are observed already from $32^{\circ} \mathrm{C}$ in the US. Conversely, Italian students mostly suffer from the negative effects of cold temperature and temperature shocks.

Gender differences confirm the findings of the previous experimental studies (Chang \& Kajackaite, 2019). Girls increase performance in math when the temperature is high and perform worse at low temperatures. Conversely, boys show a slight decrease in their performance at 
temperatures above $30^{\circ} \mathrm{C}$. Similarly, a sudden increase in temperature, relative to the day preceding the test, decreases boys math scores and slightly increases girls scores. The effect sizes of the interactions of temperature with gender is small, but substantively reduces the gender gap in math. Also, gender differences are confirmed when comparing the long-term effects of school year temperature on test scores. A higher temperature during the school year is positively associated with test scores for girls but the opposite is true for boys. Out of school exposure, during festivities and weekends, show similar findings with a positive effect of higher temperature on math test scores. Chang \& Kajackaite (2018) explained gender differences with effort, boys showing lower number of answers given at high temperatures and the opposite for girls. I conducted quantile regression of the bottom 20 and top 80 to observe heterogeneity in the effects of temperature on math that could be related to effort. Interestingly, I observe that the bottom 20 suffers from all temperatures outside the level of comfort. Conversely, the top 80 quintile suffers only from low temperatures but not from high temperatures. These results might hint in the direction of effort in explaining the effect of temperature on performance and the gender differences observed. However, this is the first observational study to highlight gender differences in students sensibility to temperature and further studies should analyze other possible mechanisms. Nonetheless, temperature is a neglected variable, that contributes to the gender gap in math. Work and school environments should consider these differences and design spaces that are fit for boys and girls alike. Conversely, a gender neutral attitude in the design of the public space could determine biases and discrimination impairing the learning of students.

The main limitation of this study is the strong assumption on which it relies, that the cohorts of students in a province are comparable over time. However, performance might fluctuate over the years, determining possible biases on the results and affecting reliability of the causal claims. To test the robustness of the results, I run the analysis using school-fixed effects. Using school fixed effects I compare the same schools over time, improving in the comparability of the sample. However, comparing schools might hide the effect of SES, that could be absorbed by the type of school. In the analysis, the substantive findings remain unchanged. Similarly, introducing year fixed effects does not change results.

\section{Conclusion}

The risks posed by climate change and global warming increased the interest in the analysis of temperature as an exogenous stressor affecting student's performance. Heterogeneity in exposure 
and vulnerability limit generalizability of the results to all social groups and geographical contexts. Here, I inquired how temperature affected performance during the day of the test and school year learning by SES and gender in Italy. Using a measure of exposure to temperature during the timing of the test, I showed that temperature has no effect on math scores and a small negative effect on reading when analysing the whole sample and by SES. However, students are sensible to changes in temperature, especially, when these suddenly increase compared to the day preceding the test. Moreover, the results hide gender differences as girls perform better in math when the temperature is high. Conversely, boys perform worse at during hot days. Similarly, learning during the school year is negatively affected by higher temperatures but hide gender differences that are apparent once the variable of exposure is interacted with gender.

The evidence confirms previous experimental studies (Chang \& Kajackaite, 2019) and raises further attention on the importance of temperature in the work and school environment for women cognitive performance(Kingma \& Van Marken Lichtenbelt, 2015). To achieve gender equality in math girls should be provided with a comfortable classroom setting in which their capacities can flourish. Conversely, a gender neutral environment produces suboptimal outcomes for male and female students alike.

Further studies could inquire gender differences using panel data allowing to avoid strong assumptions on the comparability of the sample over time looking at the performance of the same student as in Goodman et al. (2020). Substantively, the literature could be enriched by comparative studies that might enlighten how adaptation and culture determine differences in the temperature of comfort and gender differences derived from social norms on clothing. In conclusion, a sociological approach provides and understanding of how social groups are differently affected by meteorological variables and a comprehension of the risks posed by climate change, necessary to design a fair work and school environment for all. 


\section{References}

Baker, Michael, e Kevin Milligan. «Boy-Girl Differences in Parental Time Investments: Evidence from Three Countries». Working Paper. Working Paper Series. National Bureau of Economic Research, 2013. https://doi.org/10.3386/w18893.

Barreca, Alan, Karen Clay, Olivier Deschenes, Michael Greenstone, and Joseph S. Shapiro. 'Adapting to Climate Change: The Remarkable Decline in the US Temperature-Mortality Relationship over the Twentieth Century'. Journal of Political Economy 124, no. 1 (February 2016): 105-59. https://doi.org/10.1086/684582.

Basto-Abreu, Ana, Tonatiuh Barrientos-Gutiérrez, Rodrigo Zepeda-Tello, Vanessa Camacho, David Gimeno Ruiz de Porras, and Mauricio Hernández-Ávila. 'The Relationship of Socioeconomic Status with Body Mass Index Depends on the Socioeconomic Measure Used'. Obesity 26, no. 1 (2018): 176-84. https://doi.org/10.1002/oby.22042.

Bathiany, Sebastian, Vasilis Dakos, Marten Scheffer, e Timothy M. Lenton. «Climate Models Predict Increasing Temperature Variability in Poor Countries». Science Advances 4, n. 5 (1 maggio 2018): eaar5809. https://doi.org/10.1126/sciadv.aar5809.

Baylis, Patrick, Nick Obradovich, Yury Kryvasheyeu, Haohui Chen, Lorenzo Coviello, Esteban Moro, Manuel Cebrian, and James H. Fowler. 'Weather Impacts Expressed Sentiment'. Edited by Tobias Preis. PLOS ONE 13, no. 4 (25 April 2018): e0195750. https://doi.org/10.1371/journal.pone.0195750.

Behrer, A Patrick, and Jisung Park. 'Will We Adapt? Temperature, Labor and Adaptation to Climate Change', n.d., 39.

Bernardi, Fabrizio. 'Compensatory Advantage as a Mechanism of Educational Inequality: A Regression Discontinuity Based on Month of Birth'. Sociology of Education 87, no. 2 (April 2014): 74-88. https://doi.org/10.1177/0038040714524258.

Blaabæk, Ea Hoppe. 'Reading When the Sun Does Not Shine: The Effect of Reading on Children's Academic Performance'. Research in Social Stratification and Mobility 67 (1 June 2020): 100485. https://doi.org/10.1016/j.rssm.2020.100485.

Carleton, T. A., and S. M. Hsiang. 'Social and Economic Impacts of Climate'. Science 353, no. 6304 (2016): aad9837-aad9837. https://doi.org/10.1126/science.aad9837.

Chang, Tom Y., and Agne Kajackaite. 'Battle for the Thermostat: Gender and the Effect of Temperature on Cognitive Performance'. Edited by Valerio Capraro. PLOS ONE 14, no. 5 (22 May 2019): e0216362. https://doi.org/10.1371/journal.pone.0216362.

Cho, Hyunkuk. 'The Effects of Summer Heat on Academic Achievement: A Cohort Analysis'. Journal of Environmental Economics and Management 83 (May 2017): 185-96. https://doi.org/10.1016/j.jeem.2017.03.005.

Côté, Julie N. «A Critical Review on Physical Factors and Functional Characteristics That May Explain a Sex/Gender Difference in Work-Related Neck/Shoulder Disorders». Ergonomics 55, n. 2 (2012): 173-82. https://doi.org/10.1080/00140139.2011.586061.

Daganzo, Mary Angeline A., and Allan B. I. Bernardo. 'Socioeconomic Status and Problem Attributions: The Mediating Role of Sense of Control'. Edited by Juliet Wakefield. Cogent Psychology 5, no. 1 (1 January 2018): 1525149. https://doi.org/10.1080/23311908.2018.1525149.

Díaz, J., R. Carmona, I.J. Mirón, M.Y. Luna, and C. Linares. 'Time Trend in the Impact of Heat Waves on Daily Mortality in Spain for a Period of over Thirty Years (1983-2013)'. Environment International 116 (July 2018): 10-17. https://doi.org/10.1016/j.envint.2018.04.001.

Dietz, Thomas, Rachael L. Shwom, and Cameron T. Whitley. 'Climate Change and Society'. 
Annual Review of Sociology 46, no. 1 (2020): null. https://doi.org/10.1146/annurev-soc121919-054614.

Dossi, Gaia, David Figlio, Paola Giuliano, e Paola Sapienza. «Born in the Family: Preferences for Boys and the Gender Gap in Math». Cambridge, MA: National Bureau of Economic Research, febbraio 2019. https://doi.org/10.3386/w25535.

Dunne, John P., Ronald J. Stouffer, and Jasmin G. John. 'Reductions in Labour Capacity from Heat Stress under Climate Warming'. Nature Climate Change 3, no. 6 (June 2013): 563-66. https://doi.org/10.1038/nclimate1827.

Heal, Geoffrey, and Jisung Park. 'Reflections-Temperature Stress and the Direct Impact of Climate Change: A Review of an Emerging Literature'. Review of Environmental Economics and Policy 10, no. 2 (July 2016): 347-62. https://doi.org/10.1093/reep/rew007.

Karjalainen, S. 'Thermal Comfort and Gender: A Literature Review: Thermal Comfort and Gender : A Literature Review'. Indoor Air 22, no. 2 (April 2012): 96-109. https://doi.org/10.1111/j.1600-0668.2011.00747.x.

Kingma, Boris, and Wouter van Marken Lichtenbelt. 'Energy Consumption in Buildings and Female Thermal Demand'. Nature Climate Change 5, no. 12 (December 2015): 1054-56. https://doi.org/10.1038/nclimate2741.

Kjellstrom, Tord, David Briggs, Chris Freyberg, Bruno Lemke, Matthias Otto, and Olivia Hyatt. 'Heat, Human Performance, and Occupational Health: A Key Issue for the Assessment of Global Climate Change Impacts'. Annual Review of Public Health 37, no. 1 (18 March 2016): 97-112. https://doi.org/10.1146/annurev-publhealth-032315-021740.

Klinenberg, Eric, Malcolm Araos, and Liz Koslov. 'Sociology and the Climate Crisis'. Annual Review of Sociology 46, no. 1 (2020): null. https://doi.org/10.1146/annurev-soc-121919054750 .

Kropko, Jonathan, and Robert Kubinec. 'Interpretation and Identification of Within-Unit and CrossSectional Variation in Panel Data Models'. Edited by Talib Al-Ameri. PLOS ONE 15, no. 4 (21 April 2020): e0231349. https://doi.org/10.1371/journal.pone.0231349.

Laidley, Thomas, and Dalton Conley. 'The Effects of Active and Passive Leisure on Cognition in Children: Evidence from Exogenous Variation in Weather'. Social Forces 97, no. 1 (1 September 2018): 129-56. https://doi.org/10.1093/sf/soy020.

Marken Lichtenbelt, Wouter D. van, and Boris R. Kingma. 'Building and Occupant Energetics: A Physiological Hypothesis'. Architectural Science Review 56, no. 1 (February 2013): 48-53. https://doi.org/10.1080/00038628.2012.759377.

Muller, Matthew D., John Gunstad, Michael L. Alosco, Lindsay A. Miller, John Updegraff, Mary Beth Spitznagel, e Ellen L. Glickman. «Acute cold exposure and cognitive function: evidence for sustained impairment». Ergonomics 55, n. 7 (1 luglio 2012): 792-98. https://doi.org/10.1080/00140139.2012.665497.

Nybo, Lars, Peter Rasmussen, and Michael N Sawka. 'Performance in the Heat-Physiological Factors of Importance for Hyperthermia-Induced Fatigue'. Comprehensive Physiology 4 (2014): 34.

Obradovich, Nick, Robyn Migliorini, Sara C. Mednick, and James H. Fowler. 'Nighttime Temperature and Human Sleep Loss in a Changing Climate'. Science Advances 3, no. 5 (May 2017): e1601555. https://doi.org/10.1126/sciadv.1601555.

Ogoh, Shigehiko, Kohei Sato, Kazunobu Okazaki, Tadayoshi Miyamoto, Ai Hirasawa, Keiko Morimoto, and Manabu Shibasaki. 'Blood Flow Distribution during Heat Stress: Cerebral and Systemic Blood Flow'. Journal of Cerebral Blood Flow \& Metabolism 33, no. 12 (December 2013): 1915-20. https://doi.org/10.1038/jcbfm.2013.149.

Okamoto-Mizuno, Kazue, and Koh Mizuno. 'Effects of Thermal Environment on Sleep and Circadian Rhythm'. Journal of Physiological Anthropology 31, no. 1 (December 2012): 14. https://doi.org/10.1186/1880-6805-31-14.

Park, Jisung. 'Hot Temperature and High Stakes Exams: Evidence from New York City Public 
Schools', n.d., 39 .

Park, R. Jisung, Joshua Goodman, Michael Hurwitz, and Jonathan Smith. 'Heat and Learning'. American Economic Journal: Economic Policy 12, no. 2 (May 2020): 306-39. https://doi.org/10.1257/pol.20180612.

Perez, Caroline Criado. Invisible Women: Exposing Data Bias in a World Designed for Men. Chatto \& Windus, 2019.

Pilcher, June J., Eric Nadler, e Caroline Busch. «Effects of hot and cold temperature exposure on performance: a meta-analytic review». Ergonomics 45, n. 10 (1 agosto 2002): 682-98. https://doi.org/10.1080/00140130210158419.

Samuel, Henry, Justin Huggler, and Nick Squires. 'France Postpones National Diploma Exams as Europe Endures "record” Heatwave'. The Telegraph, 25 June 2019.

https://www.telegraph.co.uk/news/2019/06/25/france-postpones-national-diploma-examsconcerns-pupils-could/.

Schweiker, Marcel, Gesche M. Huebner, Boris R. M. Kingma, Rick Kramer, and Hannah Pallubinsky. 'Drivers of Diversity in Human Thermal Perception - A Review for Holistic Comfort Models'. Temperature 5, no. 4 (2 October 2018): 308-42. https://doi.org/10.1080/23328940.2018.1534490.

Seppanen, Olli, William J. Fisk, e Q. H. Lei. «Effect of Temperature on Task Performance in Office Environment», 2006. https://escholarship.org/uc/item/45g4n3rv\#main.

Slagsvold, Britt, and Annemette Sørensen. 'Age, Education, and the Gender Gap in the Sense of Control'. International Journal of Aging \& Human Development 67, no. 1 (2008): 25-42. https://doi.org/10.2190/AG.67.1.b.

Stouffer, R. J., e R. T. Wetherald. «Changes of Variability in Response to Increasing Greenhouse Gases. Part I: Temperature». Journal of Climate 20, n. 21 (1 novembre 2007): 5455-67. https://doi.org/10.1175/2007JCLI1384.1.

Taylor, Ethel V., Ambarish Vaidyanathan, W. Dana Flanders, Matthew Murphy, Merianne Spencer, and Rebecca S. Noe. 'Differences in Heat-Related Mortality by Citizenship Status: United States, 2005-2014'. American Journal of Public Health 108, no. S2 (April 2018): S131-36. https://doi.org/10.2105/AJPH.2017.304006.

Taylor, Lee, Samuel L. Watkins, Hannah Marshall, Ben J. Dascombe, e Josh Foster. «The Impact of Different Environmental Conditions on Cognitive Function: A Focused Review». Frontiers in Physiology 6 (6 gennaio 2016). https://doi.org/10.3389/fphys.2015.00372.

Torche, Florencia. 'Prenatal Exposure to an Acute Stressor and Children's Cognitive Outcomes'. Demography 55, no. 5 (October 2018): 1611-39. https://doi.org/10.1007/s13524-018-07009. 


\section{Tables and figures}

Table 1: INVALSI test takers and date from 2013 to 2017

$\begin{array}{llll}\text { Year } & \text { Date of INVALSI test } & \mathrm{N}^{\circ} \text { of total sample } & \mathrm{N}^{\circ} \text { after listwise deletion } \\ 2013 & \text { 17 June } & 518,457 & 313,725 \\ 2014 & \text { 19 June } & 520,917 & 328,373 \\ 2015 & \text { 19 June } & 528,453 & 356,134 \\ 2016 & \text { 16 June } & 524,161 & 362,091 \\ 2017 & \text { 15 June } & 530,981 & 348,969 \\ \text { Total } & & 2,622,969 & 1,709,292\end{array}$


Table 2: Temperature on the day of the test, temperature change and Math and Reading results

\begin{tabular}{|c|c|c|c|c|}
\hline & (1) & (2) & (3) & (4) \\
\hline VARIABLES & Mathematics & Reading & Mathematics & Reading \\
\hline \multicolumn{5}{|l|}{ Temperature: } \\
\hline \multirow[t]{2}{*}{$<10{ }^{\circ} \mathrm{C}$} & $-0.17764 * * *$ & -0.00962 & $-0.19226 * * *$ & -0.01253 \\
\hline & (0.03699) & $(0.00912)$ & $(0.03700)$ & $(0.00914)$ \\
\hline \multirow[t]{2}{*}{$10-15^{\circ} \mathrm{C}$} & $-0.09519 * * *$ & -0.00680 & $-0.10434 * * *$ & $-0.00943^{*}$ \\
\hline & $(0.01118)$ & $(0.00366)$ & $(0.01120)$ & $(0.00369)$ \\
\hline \multirow[t]{2}{*}{$15-20{ }^{\circ} \mathrm{C}$} & -0.00335 & -0.00145 & $-0.00789 * *$ & -0.00196 \\
\hline & $(0.00297)$ & $(0.00124)$ & $(0.00299)$ & $(0.00126)$ \\
\hline \multirow[t]{2}{*}{$25-30^{\circ} \mathrm{C}$} & $0.00521 * *$ & 0.00040 & $0.00569 * *$ & -0.00062 \\
\hline & $(0.00185)$ & $(0.00112)$ & $(0.00187)$ & $(0.00114)$ \\
\hline \multirow[t]{2}{*}{$>30^{\circ} \mathrm{C}$} & -0.00627 & $-0.00976^{*}$ & $0.00855^{*}$ & $-0.01021 *$ \\
\hline & $(0.00360)$ & $(0.00435)$ & $(0.00389)$ & $(0.00452)$ \\
\hline
\end{tabular}

Temperature change:

$<-3$

$$
\begin{array}{ll}
0.01854 * * * & -0.00433 * \\
(0.00464) & (0.00179) \\
0.02670 * * * & 0.00440 * * * \\
(0.00210) & (0.00102) \\
-0.00619 * & 0.00060 \\
(0.00313) & (0.00221) \\
-0.01634 * * * & -0.00753 * \\
(0.00444) & (0.00373)
\end{array}
$$$$
-3 \text { to } 0
$$$$
3 \text { to } 7
$$$$
>7
$$

$\begin{array}{lcccc}\text { Constant } & -0.15724 * * * & -0.13727 * * * & -0.16299 * * * & -0.13461 * * * \\ & (0.00202) & (0.00107) & (0.00211) & (0.00115) \\ \text { Observations } & 1,709,241 & 1,708,961 & 1,709,241 & 1,708,961 \\ \text { R-squared } & 0.08339 & 0.05967 & 0.08348 & 0.05970\end{array}$




\begin{tabular}{lcccc} 
Provinces & 110 & 110 & 110 & 110 \\
Controls & YES & YES & YES & YES \\
Province FE & YES & YES & YES & YES \\
\hline
\end{tabular}

Standard errors in parentheses

$* * * \mathrm{p}<0.001, * * \mathrm{p}<0.01, * \mathrm{p}<0.05$

Table 3: School-year mean temperature and interaction with SES and gender

\begin{tabular}{|c|c|c|c|c|c|c|}
\hline & (1) & (2) & (3) & (4) & (5) & (6) \\
\hline VARIABLES & Mathematics & Reading & Mathematics & Reading & Mathematics & Reading \\
\hline \multirow{2}{*}{$\begin{array}{l}\text { School-year } \\
\text { temperature }\end{array}$} & $-0.01281 * * *$ & $-0.00569 * * *$ & $-0.01018 * *$ & $-0.00888^{* * *}$ & $-0.02186^{* * *}$ & $-0.00373 * * *$ \\
\hline & $(0.00130)$ & $(0.00069)$ & $(0.00406)$ & $(0.00181)$ & $(0.00395)$ & $(0.00089)$ \\
\hline \multirow{3}{*}{$\begin{array}{c}\text { Middle- } \\
\text { SES\#Temperature }\end{array}$} & & & -0.00115 & $0.00790 * * *$ & & \\
\hline & & & & & & \\
\hline & & & $(0.00190)$ & $(0.00260)$ & & \\
\hline \multirow{3}{*}{$\begin{array}{c}\text { High- } \\
\text { SES\#Temperature }\end{array}$} & & & -0.00556 & $0.00914 *$ & & \\
\hline & & & & & & \\
\hline & & & $(0.00470)$ & $(0.00486)$ & & \\
\hline \multirow[t]{2}{*}{ Female\#Temperature } & & & & & $0.02232 * * *$ & -0.00021 \\
\hline & & & & & $(0.00270)$ & $(0.00047)$ \\
\hline \multirow[t]{2}{*}{ Constant } & -0.01735 & $-0.07557 * * *$ & -0.05126 & -0.03440 & $0.08703 *$ & $-0.08090 * * *$ \\
\hline & $(0.01430)$ & $(0.00757)$ & $(0.04924)$ & $(0.02451)$ & $(0.04216)$ & $(0.01806)$ \\
\hline Observations & $1,709,241$ & $1,708,961$ & $1,709,241$ & $1,708,961$ & $1,709,241$ & $1,708,961$ \\
\hline Controls & YES & YES & YES & YES & YES & YES \\
\hline Province FE & YES & YES & YES & YES & YES & YES \\
\hline
\end{tabular}

Standard errors in parentheses

$* * * \mathrm{p}<0.001, * * \mathrm{p}<0.01, * \mathrm{p}<0.05$ 
Table 4: Festivities mean temperature and interaction with SES and sex

\begin{tabular}{|c|c|c|c|c|c|c|}
\hline & (1) & (2) & (3) & (4) & (5) & (6) \\
\hline VARIABLES & Mathematics & Reading & Mathematics & Reading & Mathematics & Reading \\
\hline \multirow[t]{2}{*}{ Out of school temperature } & $0.02936^{* * *}$ & -0.00036 & $0.03124 * * *$ & $-0.00711^{* *}$ & $0.01946^{* * *}$ & -0.00005 \\
\hline & $(0.00299)$ & $(0.00155)$ & $(0.00349)$ & $(0.00260)$ & $(0.00320)$ & $(0.00157)$ \\
\hline \multirow[t]{2}{*}{ Middle-SES\#Temperature } & & & -0.00196 & $0.01020 * *$ & & \\
\hline & & & $(0.00209)$ & $(0.00326)$ & & \\
\hline \multirow[t]{2}{*}{ High-SES\#Temperature } & & & -0.00794 & $0.01177^{*}$ & & \\
\hline & & & $(0.00505)$ & $(0.00552)$ & & \\
\hline \multirow[t]{2}{*}{ Female\#Temperature } & & & & & $0.01979 * * *$ & -0.00062 \\
\hline & & & & & $(0.00243)$ & $(0.00047)$ \\
\hline \multirow[t]{2}{*}{ Constant } & $-0.46887 * * *$ & $-0.13657 * * *$ & $-0.48963 * * *$ & $-0.06314^{*}$ & $-0.36536 * * *$ & $-0.13981 * * *$ \\
\hline & $(0.03927)$ & $(0.02069)$ & $(0.04413)$ & $(0.02813)$ & $(0.03840)$ & $(0.02128)$ \\
\hline Observations & $1,709,241$ & $1,708,961$ & $1,696,756$ & $1,696,476$ & $1,696,756$ & $1,696,476$ \\
\hline Controls & YES & YES & YES & YES & YES & YES \\
\hline Province FE & YES & YES & YES & YES & YES & YES \\
\hline
\end{tabular}

Standard errors in parentheses

$* * * \mathrm{p}<0.001, * * \mathrm{p}<0.01, * \mathrm{p}<0.05$ 
Figure 1: Correlation between temperature and Test scores

\section{Correlation of Temperature and test scores}

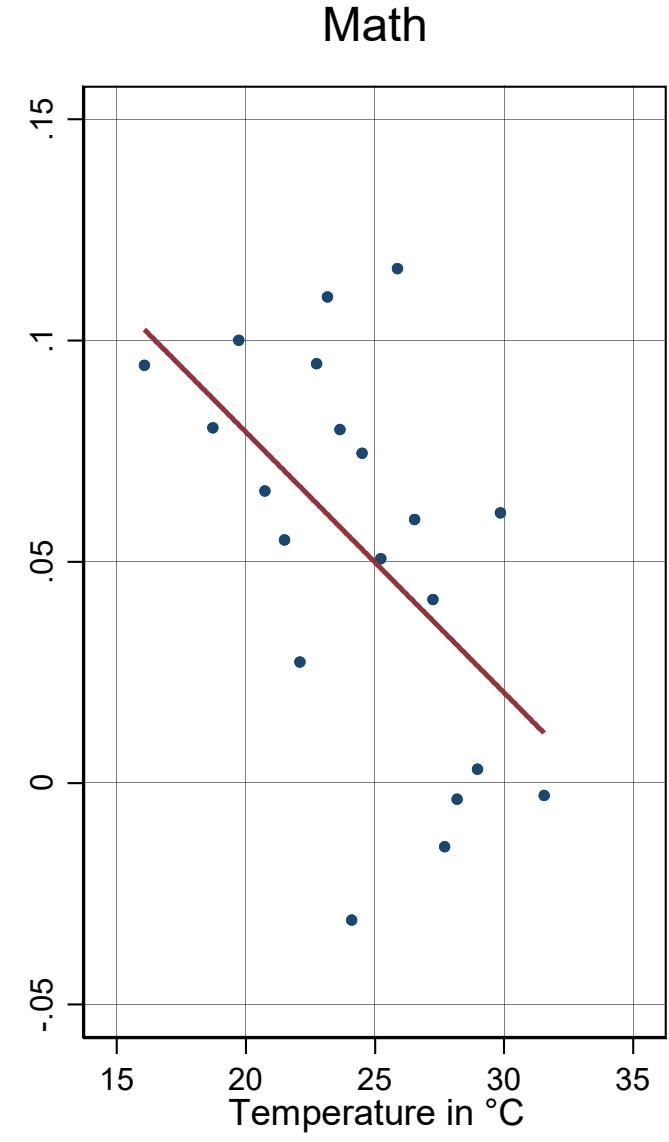

Beta coefficient $=-0.006$

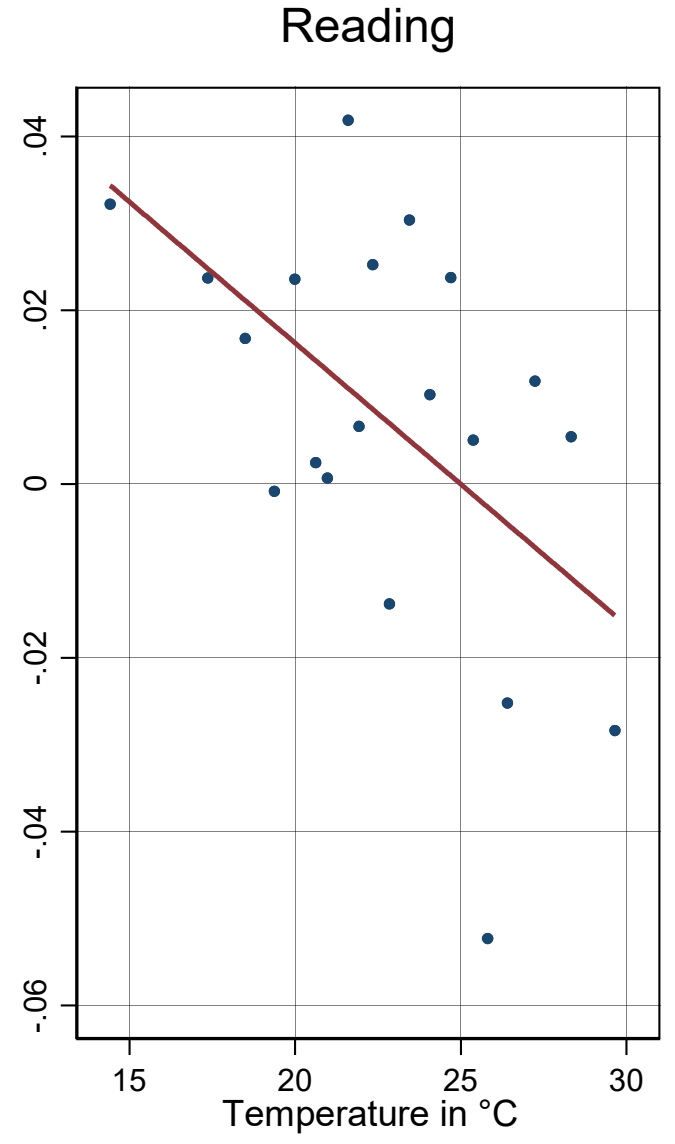

Beta coefficient $=-0.003$ 


\section{Heterogeneuos effects of Temperature}
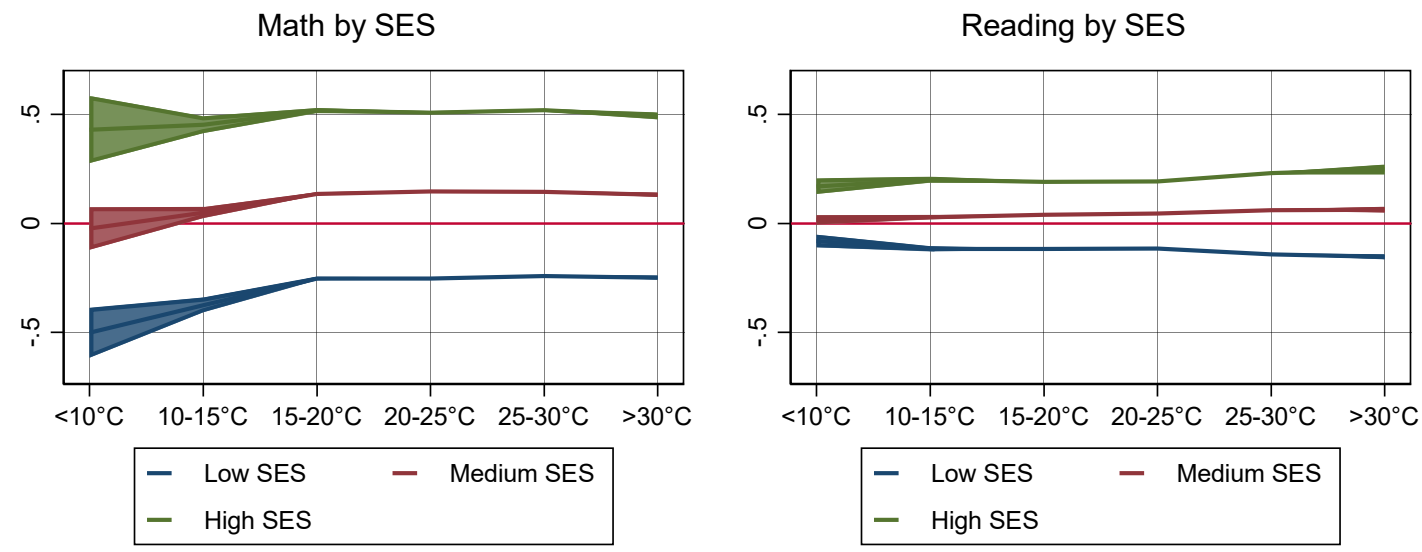

Math by gender

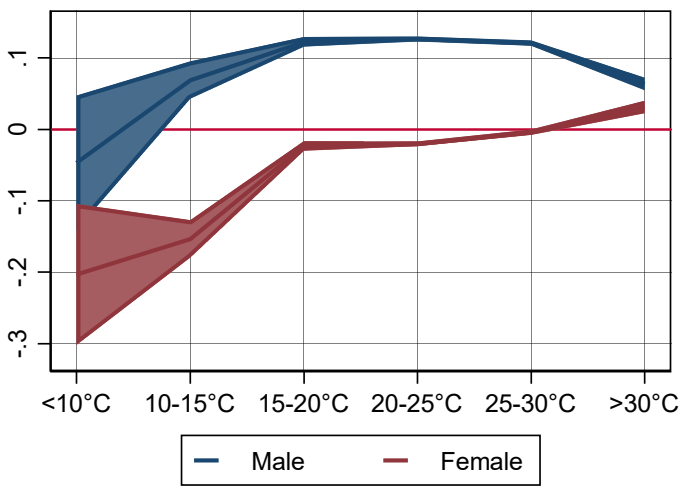

Reading by gender

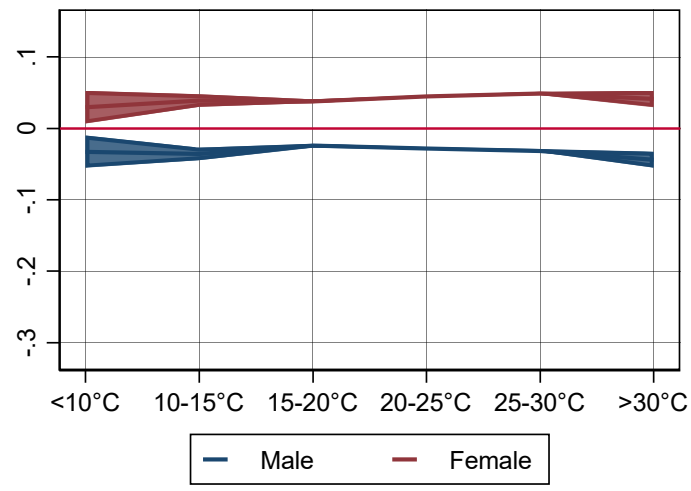


Figure 3: Temperature change and gender heterogeneity

\section{Effects of temperature change by gender}
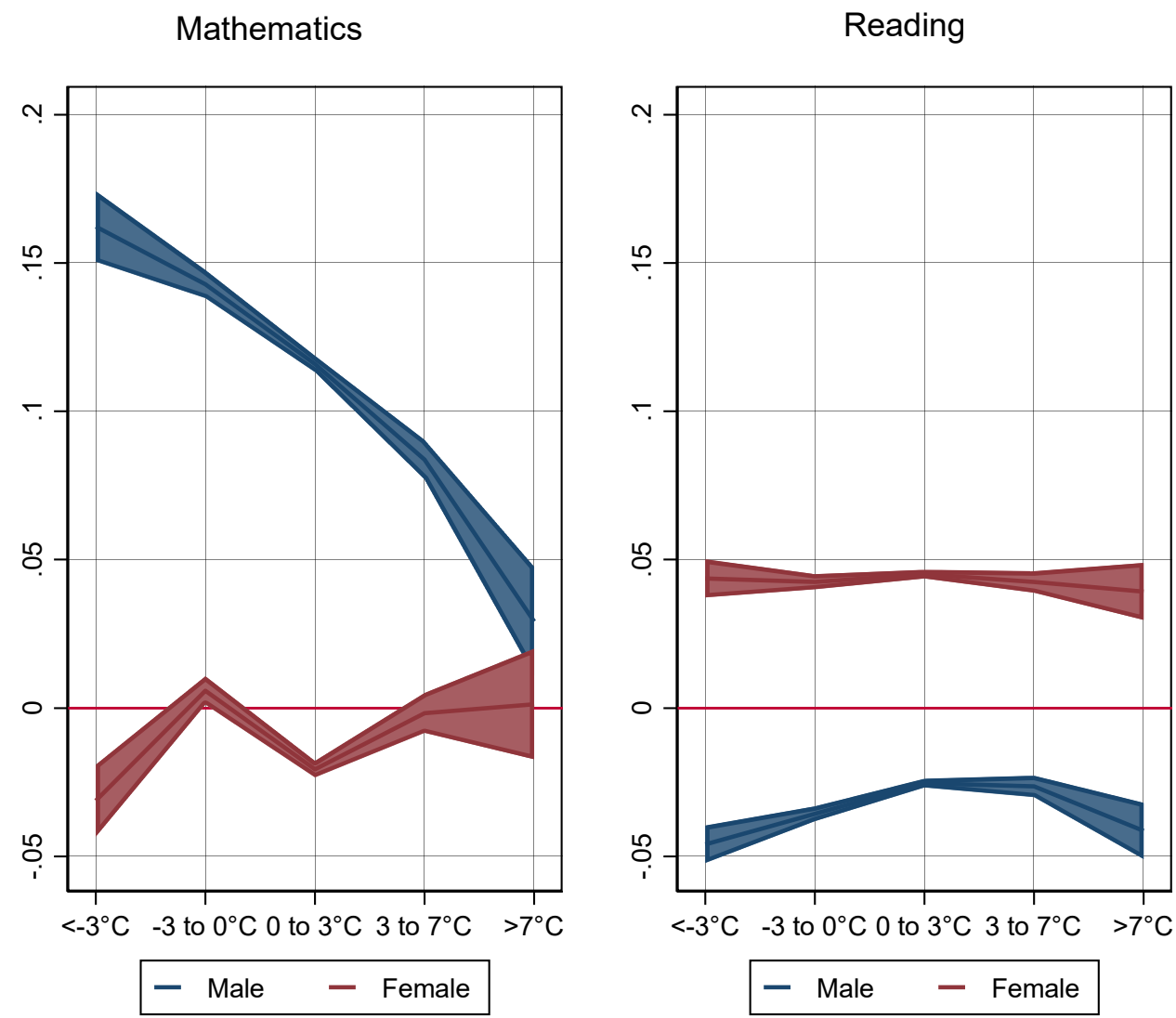


\section{Appendix}

Figure A: Temperature on the day of the test by year

\section{Temperature on the day of the test by year}

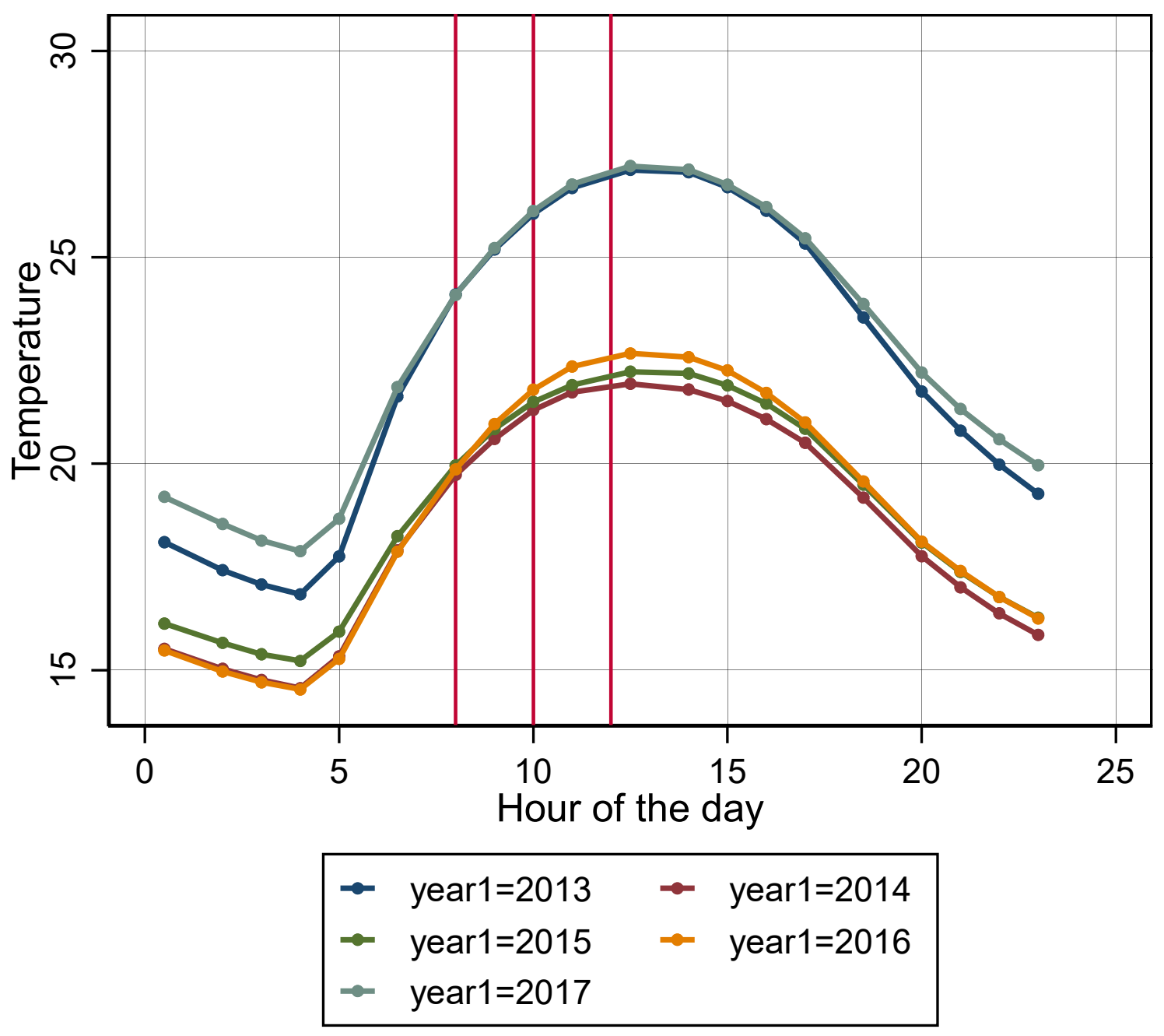


Table A: Temperature on the day of the test and heterogeneity

\begin{tabular}{|c|c|c|c|c|}
\hline VARIABLES & $\begin{array}{c}\text { (1) } \\
\text { Mathematics }\end{array}$ & $\begin{array}{c}(2) \\
\text { Reading } \\
\end{array}$ & $\begin{array}{c}\text { (3) } \\
\text { Mathematics }\end{array}$ & $\begin{array}{c}(4) \\
\text { Reading } \\
\end{array}$ \\
\hline \multicolumn{5}{|l|}{ Temperature } \\
\hline$<10^{\circ} \mathrm{C}$ & $\begin{array}{c}-0.24845 * * * \\
(0.05839)\end{array}$ & $\begin{array}{l}0.03414 * \\
(0.01469)\end{array}$ & $\begin{array}{c}-0.17324 * * * \\
(0.04800)\end{array}$ & $\begin{array}{l}-0.00441 \\
(0.01150)\end{array}$ \\
\hline $10-15^{\circ} \mathrm{C}$ & $\begin{array}{c}-0.12066^{* * * *} \\
(0.01738)\end{array}$ & $\begin{array}{l}-0.00117 \\
(0.00576)\end{array}$ & $\begin{array}{c}-0.05749 * * * \\
(0.01350)\end{array}$ & $\begin{array}{l}-0.00780 \\
(0.00459)\end{array}$ \\
\hline $15-20^{\circ} \mathrm{C}$ & $\begin{array}{c}0.00150 \\
(0.00450)\end{array}$ & $\begin{array}{l}-0.00018 \\
(0.00189)\end{array}$ & $\begin{array}{l}-0.00400 \\
(0.00382)\end{array}$ & $\begin{array}{l}0.00385^{*} \\
(0.00163)\end{array}$ \\
\hline $25-30^{\circ} \mathrm{C}$ & $\begin{array}{c}0.01241^{* * *} \\
(0.00288)\end{array}$ & $\begin{array}{c}-0.02773 * * * \\
(0.00162)\end{array}$ & $\begin{array}{l}-0.00578^{*} \\
(0.00252)\end{array}$ & $\begin{array}{l}-0.00321^{*} \\
(0.00146)\end{array}$ \\
\hline$>30^{\circ} \mathrm{C}$ & $\begin{array}{c}0.00557 \\
(0.00497)\end{array}$ & $\begin{array}{c}-0.04476^{* * *} \\
(0.00582)\end{array}$ & $\begin{array}{c}-0.06306^{* * * *} \\
(0.00472)\end{array}$ & $\begin{array}{c}-0.01584 * * \\
(0.00575)\end{array}$ \\
\hline $\begin{array}{l}\text { Temperature \& SES: } \\
<10^{\circ} \mathrm{C} \text { Medium-SES }\end{array}$ & $\begin{array}{c}0.07816 \\
(0.07246)\end{array}$ & $\begin{array}{c}-0.06268 * * * \\
(0.01658)\end{array}$ & & \\
\hline$<10^{\circ} \mathrm{C} \#$ High-SES & $\begin{array}{c}0.16977 \\
(0.09447)\end{array}$ & $\begin{array}{l}-0.05515^{*} \\
(0.02192)\end{array}$ & & \\
\hline 10-15 ${ }^{\circ} \mathrm{C} \#$ Medium-SES & $\begin{array}{c}0.02298 \\
(0.01825)\end{array}$ & $\begin{array}{l}-0.01492^{*} \\
(0.00651)\end{array}$ & & \\
\hline 10-15 ${ }^{\circ} \mathrm{CHHigh-SES}$ & $\begin{array}{l}0.06423 * * \\
(0.02370)\end{array}$ & $\begin{array}{c}0.01039 \\
(0.00837)\end{array}$ & & \\
\hline $15-20^{\circ} \mathrm{C} \#$ Medium-SES & $\begin{array}{l}-0.01258 * \\
(0.00542)\end{array}$ & $\begin{array}{l}-0.00353 \\
(0.00235)\end{array}$ & & \\
\hline $15-20^{\circ} \mathrm{CHHigh-SES}$ & $\begin{array}{c}0.00758 \\
(0.00733)\end{array}$ & $\begin{array}{c}0.00136 \\
(0.00322)\end{array}$ & & \\
\hline 25-30 ${ }^{\circ} \mathrm{C} \#$ Medium-SES & $\begin{array}{c}-0.01471 * * * \\
(0.00377)\end{array}$ & $\begin{array}{c}0.04241 * * * \\
(0.00209)\end{array}$ & & \\
\hline 25-30 ${ }^{\circ} \mathrm{C} \#$ High-SES & $\begin{array}{l}-0.00240 \\
(0.00518)\end{array}$ & $\begin{array}{c}0.06434 * * * \\
(0.00289)\end{array}$ & & \\
\hline$>30^{\circ} \mathrm{C} \#$ Medium-SES & $\begin{array}{c}-0.02091 * * \\
(0.00666)\end{array}$ & $\begin{array}{c}0.05607 * * * \\
(0.00823)\end{array}$ & & \\
\hline$>30^{\circ} \mathrm{C} \#$ High-SES & $\begin{array}{l}-0.02142^{*} \\
(0.00955)\end{array}$ & $\begin{array}{c}0.09424 * * * \\
(0.01235)\end{array}$ & & \\
\hline Temperature and gender: & & & & \\
\hline$<10^{\circ} \mathrm{C} \#$ Female & & & $\begin{array}{l}-0.00952 \\
(0.06475)\end{array}$ & $\begin{array}{l}-0.01058 \\
(0.01425)\end{array}$ \\
\hline $10-15^{\circ} \mathrm{C} \#$ Female & & & $\begin{array}{l}-0.07550^{* * *} \\
(0.01519)\end{array}$ & $\begin{array}{c}0.00199 \\
(0.00555)\end{array}$ \\
\hline $15-20{ }^{\circ} \mathrm{C} \#$ Female & & & $\begin{array}{c}0.00125 \\
(0.00486)\end{array}$ & $\begin{array}{c}-0.01070^{* * *} \\
(0.00213)\end{array}$ \\
\hline $25-30{ }^{\circ} \mathrm{C} \#$ Female & & & $\begin{array}{c}0.02215^{* * * *} \\
(0.00344)\end{array}$ & $\begin{array}{c}0.00727 * * * \\
(0.00191)\end{array}$ \\
\hline$>30^{\circ} \mathrm{C} \#$ Female & & & $\begin{array}{c}0.11465 * * * \\
(0.00615)\end{array}$ & $\begin{array}{c}0.01240 \\
(0.00765)\end{array}$ \\
\hline Constant & $\begin{array}{c}-0.16139 * * * \\
(0.00233)\end{array}$ & $\begin{array}{c}-0.12784 * * * \\
(0.00122)\end{array}$ & $\begin{array}{c}-0.14941 * * * \\
(0.00221)\end{array}$ & $\begin{array}{c}-0.13725^{* * * *} \\
(0.00116)\end{array}$ \\
\hline Observations & $1,709,241$ & $1,708,961$ & $1,709,241$ & $1,708,961$ \\
\hline R-squared & 0.08342 & 0.06014 & 0.08361 & 0.05971 \\
\hline Controls & YES & YES & YES & YES \\
\hline Province FE & YES & YES & YES & YES \\
\hline
\end{tabular}

Standard errors in parentheses; ${ }^{* * *} \mathrm{p}<0.001,{ }^{* *} \mathrm{p}<0.01,{ }^{*} \mathrm{p}<0.05$ 
Table B: Temperature change and heterogeneity

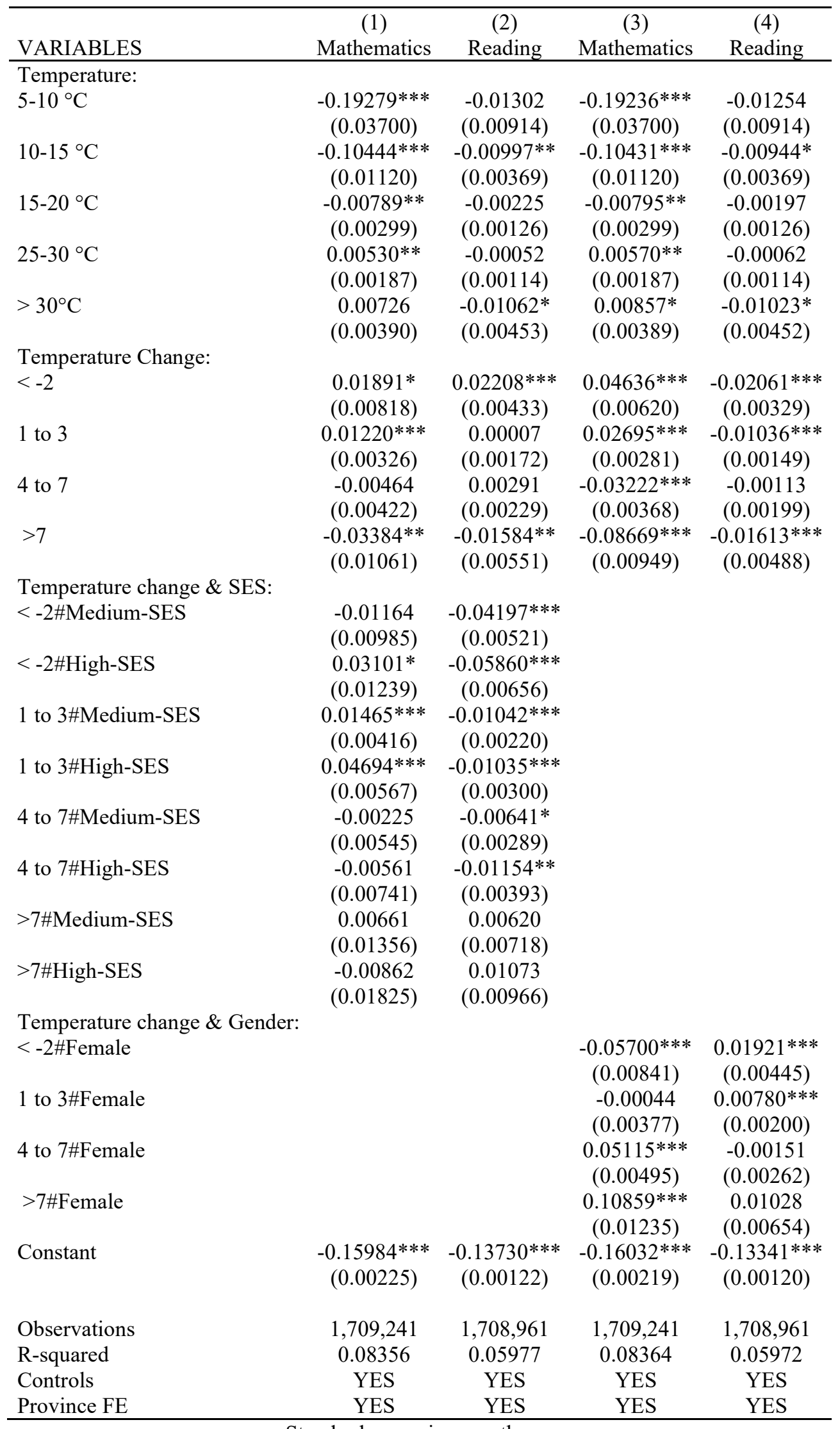


Figure B: Temperature change and heterogeneity by SES

\section{Effects of temperature change by SES}
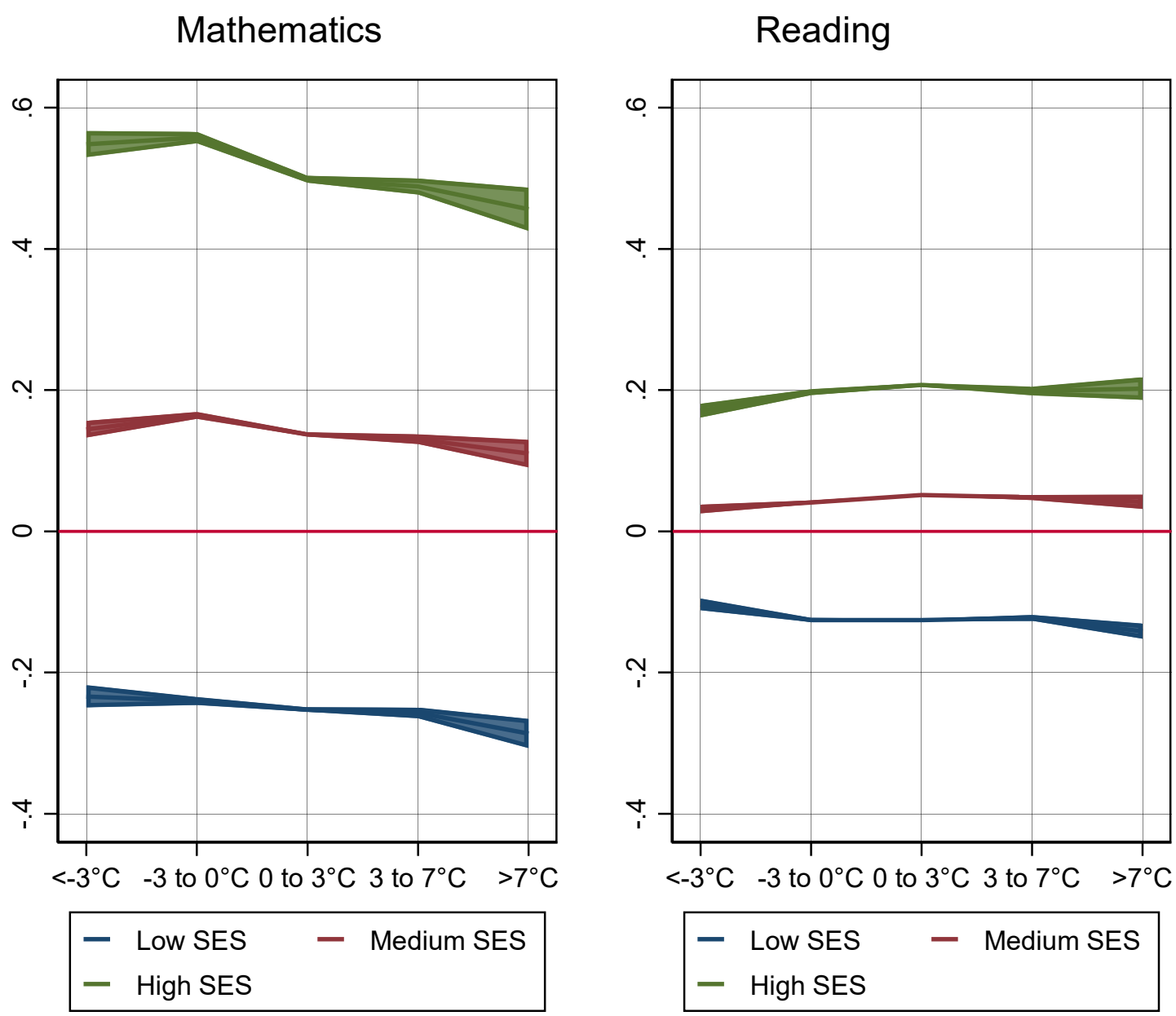
Table C: Robustness test using School Fixed Effects

\begin{tabular}{|c|c|c|c|c|}
\hline VARIABLES & $\begin{array}{c}\text { (1) } \\
\text { Mathematics }\end{array}$ & $\begin{array}{c}(2) \\
\text { Reading }\end{array}$ & $\begin{array}{c}\text { (3) } \\
\text { Mathematics }\end{array}$ & $\begin{array}{c}\text { (4) } \\
\text { Reading }\end{array}$ \\
\hline \multicolumn{5}{|l|}{ Temperature: } \\
\hline $5-10^{\circ} \mathrm{C}$ & $\begin{array}{c}-0.16275^{* * *} \\
(0.03604)\end{array}$ & $\begin{array}{l}-0.00230 \\
(0.00841)\end{array}$ & $\begin{array}{c}-0.17730 * * * \\
(0.03605)\end{array}$ & $\begin{array}{l}-0.00427 \\
(0.00842)\end{array}$ \\
\hline $10-15^{\circ} \mathrm{C}$ & $\begin{array}{c}-0.09091 * * * \\
(0.01091)\end{array}$ & $\begin{array}{l}-0.00389 \\
(0.00341)\end{array}$ & $\begin{array}{c}-0.09994 * * * \\
(0.01093)\end{array}$ & $\begin{array}{l}-0.00568 \\
(0.00343)\end{array}$ \\
\hline $15-20^{\circ} \mathrm{C}$ & $\begin{array}{l}-0.00428 \\
(0.00292)\end{array}$ & $\begin{array}{c}0.00105 \\
(0.00115)\end{array}$ & $\begin{array}{c}-0.00874 * * \\
(0.00293)\end{array}$ & $\begin{array}{c}0.00074 \\
(0.00117)\end{array}$ \\
\hline $25-30^{\circ} \mathrm{C}$ & $\begin{array}{c}0.00715^{* * *} \\
(0.00183)\end{array}$ & $\begin{array}{c}0.00085 \\
(0.00104)\end{array}$ & $\begin{array}{c}0.00726^{* * *} \\
(0.00184)\end{array}$ & $\begin{array}{c}0.00032 \\
(0.00106)\end{array}$ \\
\hline$>30^{\circ} \mathrm{C}$ & $\begin{array}{l}-0.00701^{*} \\
(0.00353)\end{array}$ & $\begin{array}{c}-0.01060^{* *} \\
(0.00407)\end{array}$ & $\begin{array}{c}0.00707 \\
(0.00382)\end{array}$ & $\begin{array}{c}-0.01101 * * \\
(0.00423)\end{array}$ \\
\hline $\begin{array}{l}\text { Temperature Change: } \\
<-2\end{array}$ & & & $\begin{array}{c}0.02358 * * * \\
(0.00455)\end{array}$ & $\begin{array}{c}-0.00618 * * \\
(0.00228)\end{array}$ \\
\hline 1 to 3 & & & $\begin{array}{l}0.02713 * * * \\
(0.00206)\end{array}$ & $\begin{array}{c}-0.00441 * * * \\
(0.00103)\end{array}$ \\
\hline 4 to 7 & & & $\begin{array}{l}-0.00611^{*} \\
(0.00271)\end{array}$ & $\begin{array}{l}-0.00104 \\
(0.00141)\end{array}$ \\
\hline$>7$ & & & $\begin{array}{c}-0.02855^{* * *} \\
(0.00718)\end{array}$ & $\begin{array}{c}-0.01000^{* *} \\
(0.00343)\end{array}$ \\
\hline Constant & $\begin{array}{c}-0.13333^{* * * *} \\
(0.00175)\end{array}$ & $\begin{array}{c}-0.10496^{* * *} \\
(0.00088)\end{array}$ & $\begin{array}{c}-0.13923^{* * *} \\
(0.00185)\end{array}$ & $\begin{array}{c}-0.10327 * * * \\
(0.00096)\end{array}$ \\
\hline Observations & $1,709,241$ & $1,708,961$ & $1,709,241$ & $1,708,961$ \\
\hline R-squared & 0.07175 & 0.03491 & 0.07175 & 0.03491 \\
\hline Controls & YES & YES & YES & YES \\
\hline Number of schools & 6,426 & 6,421 & 6,426 & 6,421 \\
\hline School FE & YES & YES & YES & YES \\
\hline
\end{tabular}


Table D: Exposure on the day of the test with Year and Province Fixed Effects

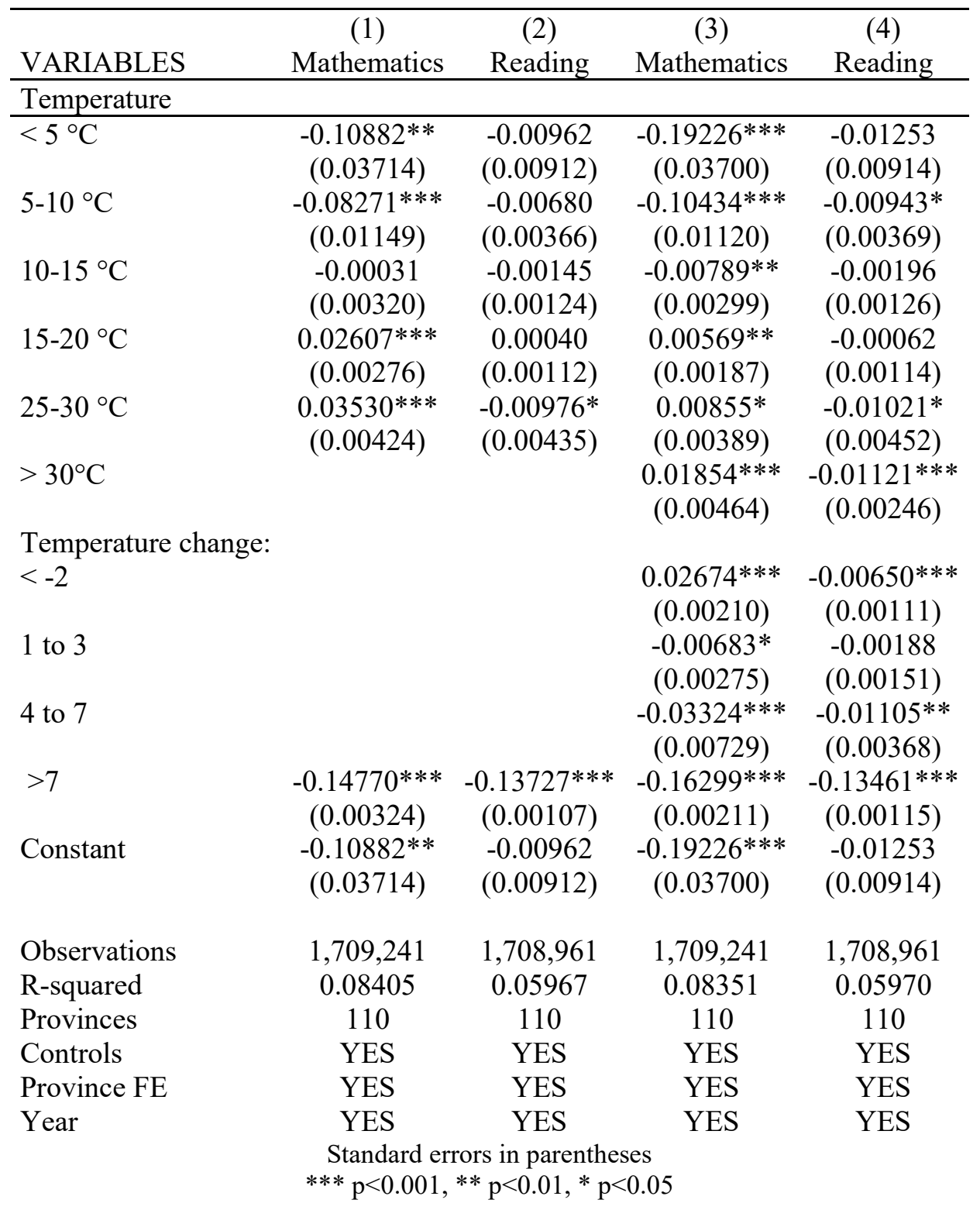


Table F: Quantile regression top 80 and bottom 20 in Mathematics

\begin{tabular}{lcc}
\hline & $(1)$ & $(2)$ \\
\hline & Top 80 & Bottom 20 \\
VARIABLES & Mathematics & Mathematics \\
\hline & & \\
$5-10{ }^{\circ} \mathrm{C}$ & $-0.16645^{* *}$ & $-0.18931^{* * *}$ \\
& $(0.05171)$ & $(0.04864)$ \\
$10-15{ }^{\circ} \mathrm{C}$ & $-0.08238^{* * *}$ & $-0.10856^{* * *}$ \\
& $(0.01690)$ & $(0.01590)$ \\
$15-20{ }^{\circ} \mathrm{C}$ & 0.00235 & $-0.00930^{*}$ \\
& $(0.00442)$ & $(0.00416)$ \\
$25-30{ }^{\circ} \mathrm{C}$ & $0.03259^{* * *}$ & $-0.02336^{* * *}$ \\
& $(0.00275)$ & $(0.00258)$ \\
$>30^{\circ} \mathrm{C}$ & $0.02548^{* * *}$ & $-0.03940^{* * *}$ \\
& $(0.00522)$ & $(0.00491)$ \\
& & $1,709,241$ \\
Observations & $1,709,241$ & YES \\
Controls & YES & YES \\
Province FE & YES \\
\hline \multicolumn{3}{c}{ Standard errors in parentheses } \\
& $* * * \mathrm{p}<0.001, * * \mathrm{p}<0.01,{ }^{*} \mathrm{p}<0.05$
\end{tabular}

